\title{
Automation of Decision-Making in the Game "Ecopoly" for Education on Relationship between Environment and Economy
}

\author{
Tatsuya Komuro* \\ Department of Industrial and Systems Engineering, Aoyama Gakuin University \\ Ayano Shinozaki \\ Department of Industrial and Systems Engineering, Aoyama Gakuin University \\ Aramu Kim \\ Department of Industrial and Systems Engineering, Aoyama Gakuin University \\ Daisuke Doyo \\ Faculty of Business Administration, Kanagawa University \\ Toshiyuki Matsumoto \\ Department of Industrial and Systems Engineering, Aoyama Gakuin University
}

(Received: September 1, 2011 / Revised: February 9, 2012 / Accepted: February 15, 2012)

\begin{abstract}
Recently, global environmental problems have become serious due to human economic activities. Therefore, in order to build a sustainable society in which human economic activities coexist with nature, it is important to promote and enhance environmental education. As a preceding study, a board and computer game of "Ecopoly," which is the game for education on global environmental problems, were developed. This study further aims to develop algorithms which make decisions in Ecopoly, to automate decision-makings of opponents using the algorithms, and to develop the environmental educational game "Ecopoly V" which enables self-learning. In order to develop the algorithms, the board game of Ecopoly was played, and each player's decision-makings at the all points at which players make a decision were observed and analyzed. From the analyses, it became clear that the decision-makings were distinguished by 3 characteristics; Ecology type, Economy type, and Balance type. Based on the characteristics, the factors and standard values of each decision-making were made clear. Algorithms were developed based on the factors and standard values. Ecopoly $\mathrm{V}$ was developed by incorporating the algorithms into the computer game of Ecopoly. Experimental testing of the game was conducted and the validity of the game was verified.
\end{abstract}

Keywords: Environmental Problem, Education, Computer Game, Decision-Making, Ecopoly

* Corresponding Author, E-mail: tatsuya-komuro@hotmail.co.jp

\section{INTRODUCTION}

In recent years, human being has been facing various kinds of environmental problems. It is therefore regarded urgent to build a sustainable society in which economic activities coexist with nature in the 21 st century. To realize such goals, it is essential to promote and enhance environmental education, and to raise global awareness of environmental issues. By providing appropriate environmental knowledge to the youth who take 
an important role in the future society, it is hoped that they can conduct economic activities taking the global environment into account. However, upon conducting environmental education based on environmental ethics, it is considered that it would take well-planned educational measures and approaches to keep the youth interested.

A preceding study has reported the development of a game called "Ecopoly" (Komuro, 2009, 2011), a board and computer game developed for educational purposes based on the Kyoto Protocol (Kaneko, 2004; Salisbury, 2005) and an acknowledged board game "Monopoly" (Suguru, 1999; Axelrod, 2004). However, with the computer version of Ecopoly, there have not yet been developed algorithms for the automation of computer opponents' decision-makings.

This study thus aims to develop algorithms which enable automation of decision-making processes of computer opponents, to realize the development of selflearning computer game "Ecopoly V." The study also aims to provide how to determine parameters for decision-making by practice observations of playing the game, to design characteristics of automated players based on them, and to develop algorithms for automated decision-making.

\section{LITERATURE REVIEW AND ECOPOLY}

\subsection{Related Literature Review}

Several preceding studies have presented effective educational methods for environmental education in the form of a game (Sugimoto, 2002; Kaneko, 2004; Kawato, 2005; Saito, 2007). For example, Sugimoto et al. proposed a collaborative learning support system using sensing boards in their study. The system enables users to learn about both city planning and environmental issues from a city level standpoint using a board game. Similarly, the game called "My Earth" (My Earth Projects LLC), a game based on trading cards, provides players with the opportunity to learn not only about global environmental linkages between living organisms, global warming and human activity, but also negotiation skills as a collaborative learning experience while having fun. By using a game for educational purposes, it may be possible to attract interest of the youth, and to educate them effectively.

\subsection{Outline of Ecopoly}

Ecopoly stands for "ECOlogy" and "monoPOLY," the former contains environmental aspects and the latter means economical aspects. This game enables players to get a general idea of $\mathrm{CO}_{2}$ emissions trading, and learn about the relationship between environmental problems and economic activities and about other environmental issues in general.

A brief outline of Ecopoly will be described as a reference here. Ecopoly is a game in which players keep moving their tokens on the map throwing 2 dice until either set turns or set time terminates. At the beginning of the game, each player is given 1500 ecos (eco is the monetary unit used in the game), 100t $\mathrm{CO}_{2}$ emission quota and $110 \mathrm{t} \mathrm{CO}_{2}$ emissions as their property. The amount left after subtracting the $\mathrm{CO}_{2}$ emissions from the $\mathrm{CO}_{2}$ emission quota is called "Hot Air." If Hot Air amount is lower than zero when the game is over, the player must pay a penalty of 50 ecos multiplied by the minus figures.

In this game, players must keep in mind that they are to achieve two goals at the same time in a wellbalanced manner; one is the environmental goal to keep the $\mathrm{CO}_{2}$ emissions within their $\mathrm{CO}_{2}$ emission quotas, and the other is the economic goal to make more money and get wealthier than other players by purchasing land or stock. The player who ends the game with the largest total properties becomes the winner. In order to achieve the environmental and economic goals, players must decide what actions below to take and when.

\subsubsection{Purchasing Land}

Each land on the map has its $\mathrm{CO}_{2}$ emission quota or $\mathrm{CO}_{2}$ emissions set according to the Kyoto Protocol. By purchasing land, players can increase or decrease their allotted $\mathrm{CO}_{2}$ emission quotas or $\mathrm{CO}_{2}$ emissions. Purchased land can be added to players' property. The player can collect charge from other players who land on the owned land.

\subsubsection{Forestation and Factory Construction}

There are 8 groups which consist of countries on the map, each colored to represent the group (hereinafter referred to as color-group). Also, the 8 groups are divided into 2 kinds of groups; one is the group of developed countries which consists of 6 color-groups, and the other is the group of developing countries which consists of 2 color-groups. If a player purchases all the land within a color-group, he/she may plant trees in the developed countries, and build factories in the developing countries. By planting trees or building factories, players can increase or decrease their allotted $\mathrm{CO}_{2}$ emissions. Also, players can increase charges which players can collect from opponents, when opponents land on the player's own property.

\subsubsection{Purchasing Stock}

Players can purchase stock during the game. Sometimes players have to pick a card according to the spaces they land. The stock players possess may increase or decrease players' money or $\mathrm{CO}_{2}$ emissions.

\subsubsection{Trading Emissions}

Players may monetarily trade their $\mathrm{CO}_{2}$ emission quotas with other players by paying money, 30 ecos per 
ton, to keep $\mathrm{CO}_{2}$ emission within its quota.

\subsubsection{Trading Land}

Player can trade their owned lands with others by adding money in order to monopolize a color group and increase $\mathrm{CO}_{2}$ emission quota.

\subsubsection{Bankruptcy}

If players run short of money during the game, they have to sell off some properties they possess. If a player is still short of money, he/she is declared bankrupt and must immediately retire from the game.

\section{METHOD OF DEVELOPMENT OF DECISION-MAKING ALGORITMS}

In order to automate players' decision-making processes, the authors observed players' decision-making processes while playing the board game version of Ecopoly. The findings and results were analyzed and characteristics of decision-making processes were specified to develop decision-making algorithms.

\subsection{Observing Players' Performances at the Board Game Ecopoly}

In order to investigate how players actually make decisions, 10 college students joined experimental game sessions using the board game Ecopoly. The experimental sessions were conducted 5 times in 750 minutes, and players' performances were observed. Each student wrote down the amount of money and Hot Air he/she possessed at each turn, the event occurred and the reasons for the actions taken. With these data, structure how to get parameters for decision-making based on what can be provided. Also value of parameters can be assigned based on simulations which have done in the following study (Tenmei, 2010), then winning percentage of each character can be managed as an educator intends.

\subsection{Analyzing Players' Decision-Making Processes}

Figure 1 shows a game process flow chart of Ecopoly. Players must make decisions on 6 matters; purchasing land, forestation and factory construction, purchasing stock, trading emissions, trading land, and bankrupt-

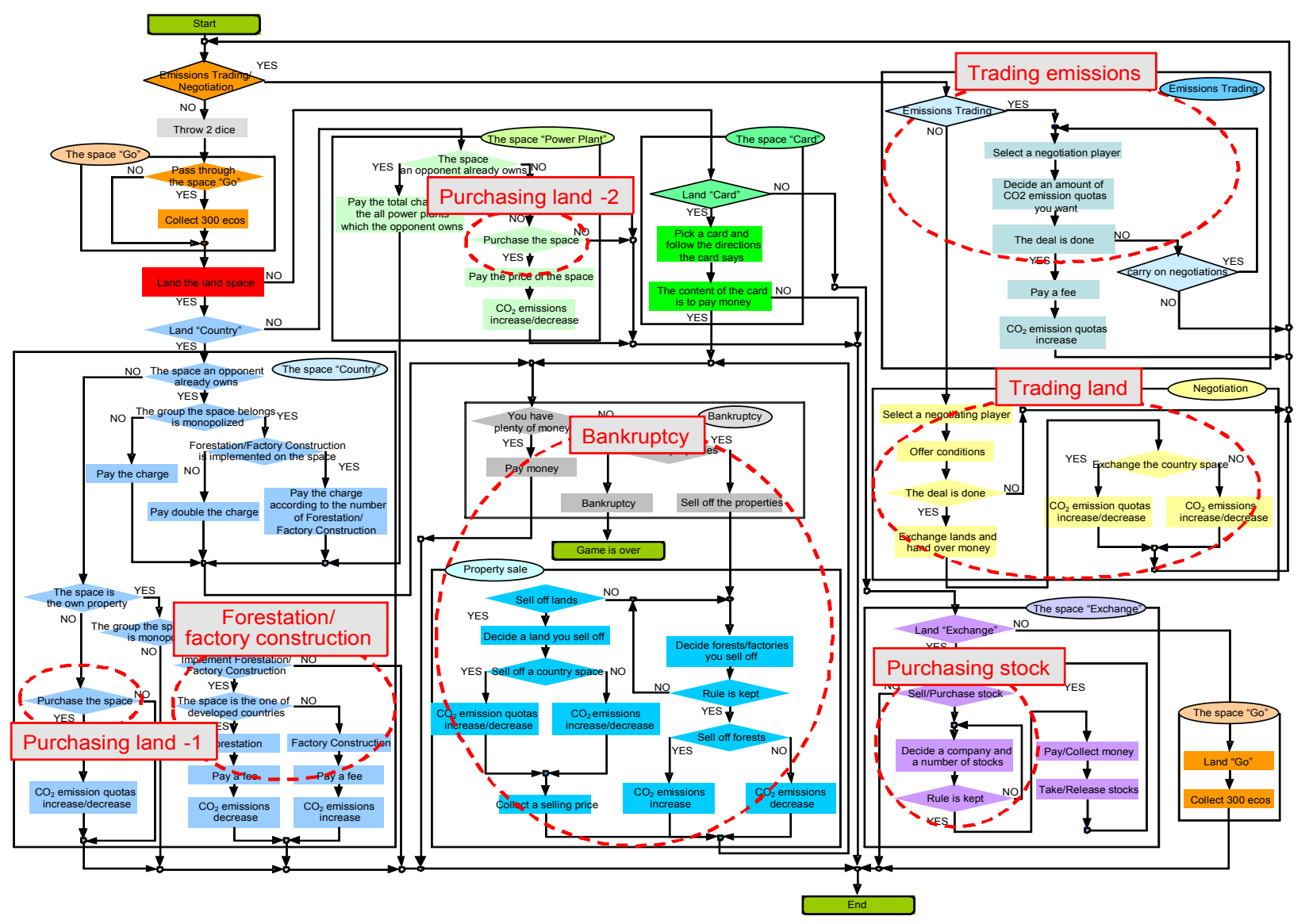

Figure 1. Game Process Flow Chart of Ecopoly. 
tcy. Decision-making processes were first categorized into the 6 matters and then analyzed according to the data players wrote down.

\subsubsection{Decision-Making on Purchasing Land}

If a player purchases land, the amount of money he/she possesses decreases and the Hot Air amount increases or decreases. The data collected from players on purchasing land related matters were analyzed from two perspectives, one is in terms of the environment, namely, the relationship between the Hot Air amount and the $\mathrm{CO}_{2}$ emission quota set for each land, the other is in terms of the economy, the relationship between the money players possess and the price of land.

\section{- In terms of the environment}

Firstly, how players take environmental aspects into account when they make decisions to purchase land was analyzed. Each piece of land has its own $\mathrm{CO}_{2}$ emission quota set between $-21 \mathrm{t}$ and $+27 \mathrm{t}$ based on the Kyoto Protocol. So, if a land's $\mathrm{CO}_{2}$ emission quota set is larger than $0 t$, there is no negative impact on the environment. If a land's $\mathrm{CO}_{2}$ emission quota is set at a negative value, lower than $0 t$, a purchase may be made for economic reasons. In order to clarify the cases where players made decisions for purely environmental reasons, the authors focused on the cases where players did not purchase land (hereinafter referred to as No Deal case) based on environmental consideration. The difference between the Hot Air amount before purchasing land and the $\mathrm{CO}_{2}$ emission quota set for each land was taken into account, and the border line for decision-making was sought. Figure 2 shows a graph generated from the data when players made decisions at No Deal cases based on environmental reasons.

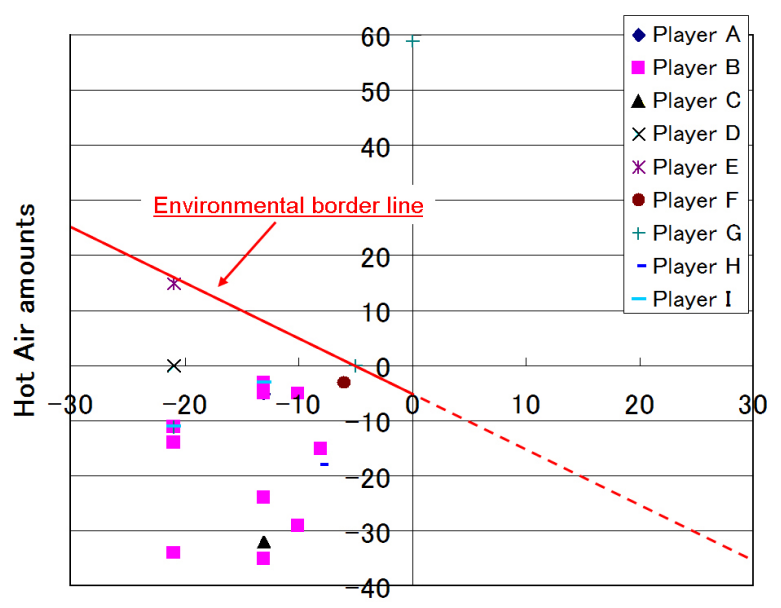

$\mathrm{CO} 2$ emission quotas which is set for each land

Figure 2. Decisions at No Deal Cases Based on Environmental Reasons.

According to Figure 2, it was found that there was no player who gave up purchasing land which provides more than $0 \mathrm{t}$ increase in $\mathrm{CO}_{2}$ emission quota for environmental reasons. Another finding was that when players did give up purchasing land, the differences between the Hot Air amount before purchasing land and the $\mathrm{CO}_{2}$ emission quota set for each land were less than $-5 \mathrm{t}$. From this, it is possible to conclude that players' decisions considering environmental factors may vary once the Hot Air amount difference becomes lower than $-5 \mathrm{t}$ due to the purchase of land. The line in Figure 2 indicates the environmental border line where decisionmaking changes arise because the Hot Air amount difference becomes lower than $-5 \mathrm{t}$.

- In terms of the economy

Secondly, how players take economic aspects into account when they make decision to purchase land was analyzed. In Ecopoly, the price of land is set between 50 and 460 ecos based on Monopoly. If players possess significantly much more money than the price set for the land, they do not hesitate to purchase the land for economic reasons. To clarify the economic border line for decision-making, the relationship between the money a player possesses and the price of land was investigated. Figure 3 shows a graph generated from the data when players made decisions at No Deal cases based on economic reasons. This number of data is small because of rare cases, so it is not sufficient but necessary one.

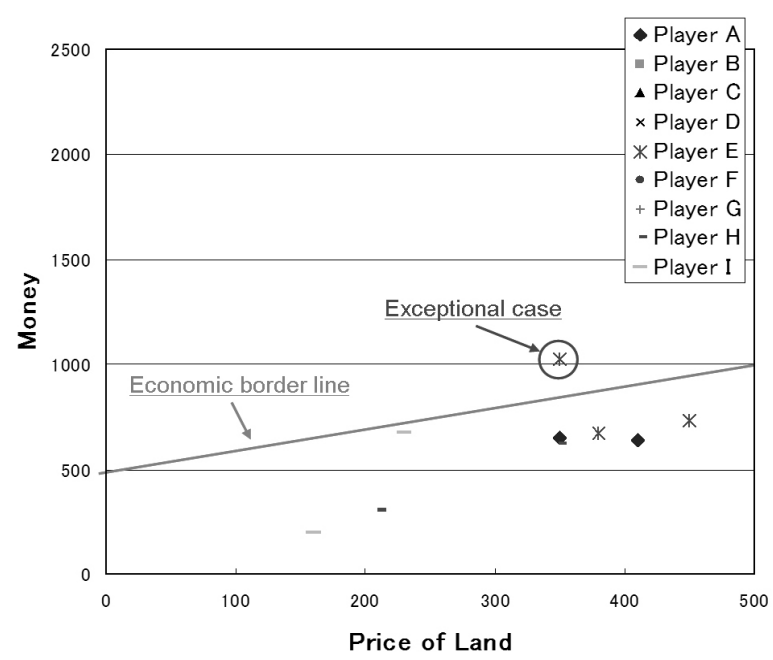

Figure 3. Decisions at No Deal Cases Based on Economic Reasons.

According to Figure 3, it was found that the differences between the money players possessed and the prices of land were equal or less than 500 ecos, excepting 1 case. In the exceptional case, it became clear that the player did not purchase the land because of the tactics the player was developing against opponents. The decision was not therefore made for the purely economic reason, so this case was excluded as an exception. It was then possible to conclude that considering eco- 
nomic factors, players may make different decisions when the amount of money left after purchasing land becomes less than 500 ecos. The line in Figure 3 is the economic border line where decision-making changes arise because the amount of money left becomes less than 500 ecos.

Observing actions players took in the games, it was found that players balance environmental aspects and economic aspects differently, so the balances vary between individuals. The differences can be roughly classified into the 3 characteristics, the environment centered players, the economy centered players and the mean players who balance both.

The environment centered players attach importance to keeping the Hot Air amount positive, and purchase land which may increase their Hot Air amount as much as possible.

The economy centered players emphasize on gaining economic superiority over opponents, rather than in terms of Hot Air decrease, so they tend to purchase expensive land which may bring them high charge in return.

The mean players reconcile keeping a certain amount of Hot Air and making money, balancing the 2 objectives when they purchase land.

These 3 characteristics identified through observation were named, "Ecology Type", "Economy Type", and "Balance Type", and were set up as computer opponents' types. Decision-making algorithms for each character were developed after that, to characterize each player's behavior upon purchasing land. Figure 4 shows the flow chart with the developed decision-making algorithms for purchasing land.

Each opponent makes decisions on purchasing land described as follows.

\section{- Ecology Type player}

Ecology Type players make decisions on purchasing land based on the Hot Air amount they possess. Analyses show that players' decisions may vary at the point where the Hot Air amount left after purchasing land indicates $-5 \mathrm{t}$, when players take environmental aspects into account. So, Ecology Type players do not purchase land when the Hot Air amount goes lower than $-5 \mathrm{t}$ after purchasing the land. To clearly characterize and distinguish each opponent's character, Ecology Type players do not care about the amount of money left after purchasing land when they make decisions on purchas-

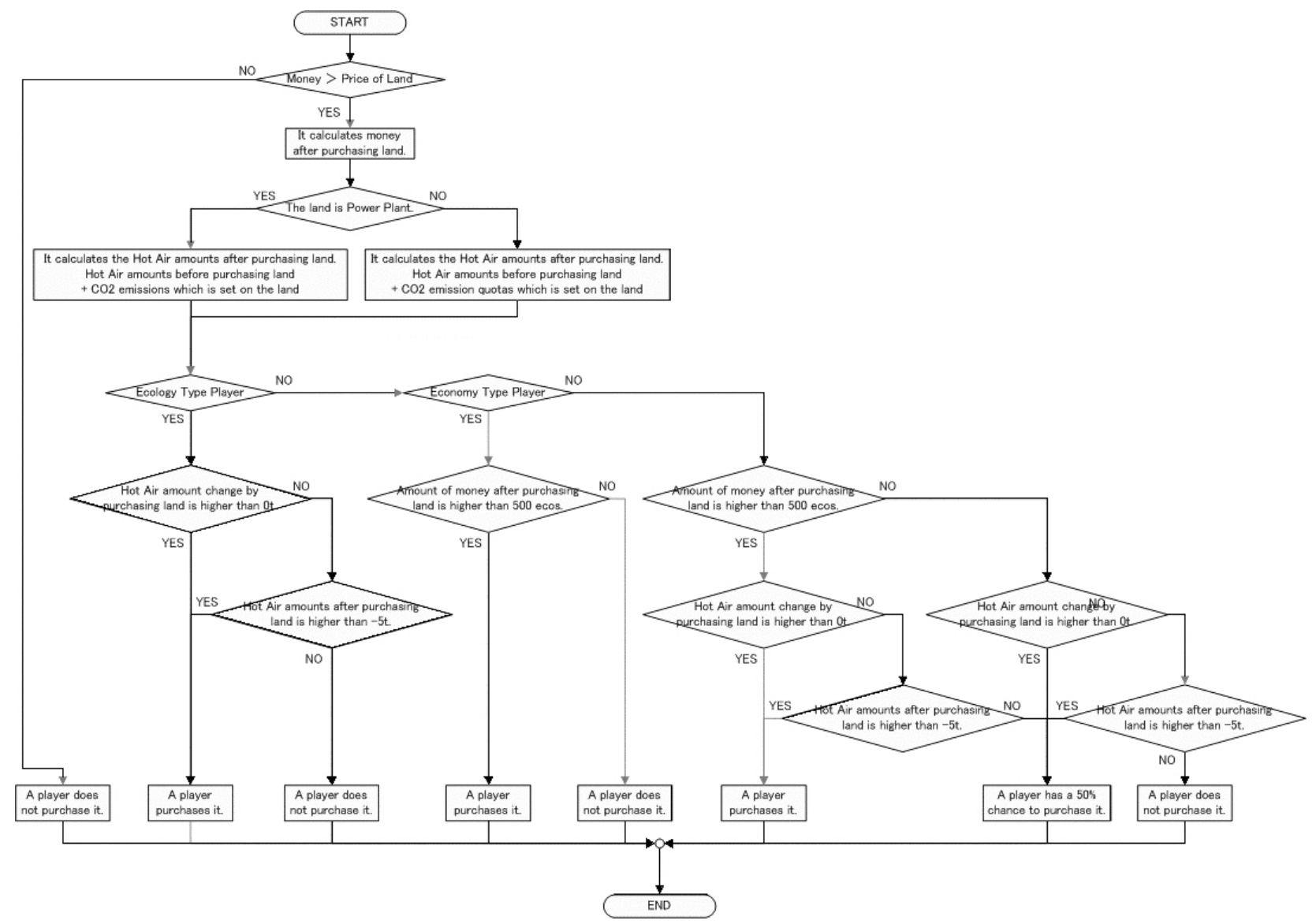

Figure 4. Flow Chart with the Developed Decision-Making Algorithms for Purchasing Land. 
ing land.

\section{- Economy Type player}

Since Economy Type players focus on making as much money as possible during the game, they make decisions based on the amount of money left after purchasing land. Analyses showed that when players take economic aspects into account, players' decisions vary at the point where the amount of money left indicates 500 ecos. So, Economy Type players do not purchase land when the amount of money left after purchasing land goes lower than 500 ecos. As in the case of Economy Type player, to clearly characterize and distinguish each opponent's character, Economy Type players do not care about the Hot Air amount left after purchasing land.

- Balance Type player

Balance Type players think about both the Hot Air amount and the amount of money left after purchasing land to make decisions. So, Balance Type players purchase land when the Hot Air amount is higher than $-5 t$ and the amount of money left is larger than 500 ecos after purchasing land. When only one of the requirements is fulfilled, the purchasing land probability drops to $50 \%$. When neither of the requirements is fulfilled, the players do not purchase land.

\subsubsection{Decision-Making on Forestation and Factory Construction}

The authors have succeeded in developing algorithms for decision-making on forestation and factory construction as in the case of purchasing land decisionmaking algorithms.

As for forestation and factory construction, the number of implementations is adjusted according to the amount of money left with players, set according to each opponent. If the left amount of money set is small, the number of implementations will increase. Likewise, if the left amount of money set is large, implementations of forestation and factory construction will decrease. The differences in the amount of money set can differentiate opponents' characters. The base amount of money left is set at 500 ecos, because it became clear that decisionmaking changes may arise at 500 ecos in the previously discussed analyses for decision-making when economic aspects are taken into account. Also, as the analyses of clarifying the economic border line 500 ecos, 2 border lines, 200 ecos and 1000 ecos, where decision-making changes may arise were clarified. The setting may also help avoid players' fund shortage due to too much forestation or factory construction.

The opponents make decisions on forestation and factory construction as follows.

\section{- Ecology Type player}

In order to reduce the $\mathrm{CO}_{2}$ emissions and increase the Hot Air amount, Ecology Type players choose to plant trees willingly when possible. On the other hand, the players are reluctant and try not to build factories since it may increase the $\mathrm{CO}_{2}$ emissions. The amount of money left is set at 200 ecos for forestation, and 1000 ecos for factory construction.

\section{- Economy Type player}

If players implement forestation or factory construction, the charge players can collect from other opponents increase, which can also increase the amount of money players possess. For this reason, Economy Type players implement forestation and factory construction willingly when possible. The amount of money left is set at 200 ecos for both forestation and factory construction. The players do not care about the $\mathrm{CO}_{2}$ emissions upon factory construction.

\section{- Balance Type player}

As on purchasing land, Balance Type players do not make one-sided decisions on forestation or factory construction by taking either environmental or economic aspects into account. For Balance Type players, the amount of money left is set at 500 ecos for both forestation and factory construction, so both can be implementted evenly.

\subsubsection{Decision-Making on Purchasing Stock}

Decision-making algorithms for purchasing stock were developed after analyzing players' behaviors as was done for purchasing land.

After reviewing the analyses, it was found that there was not much distinguishable difference according to player types. So, players use common algorithms developed for purchasing stock. Players select which company's stock to buy randomly, and the amount of money the players have determines the number of stocks to be purchased.

\subsubsection{Decision-Making on Trading Emissions}

Decision-making algorithms for trading emissions were developed after analyzing players' behaviors as was done for purchasing land. There are 2 kinds of decision-making on trading emissions; one is application, the other is acceptance in case of being applied. Application of trading emissions is judged by Hot Air amount after 20 turns over and in the middle of the game. Acceptance of trading emissions is judged by Hot Air amount and the amount of money after acceptance of the deal.

The opponents make decisions on trading emissions as follows.

\section{- Ecology Type and Balance Type player}

Ecology Type and Balance Type players make decisions on trading emissions based on safety amount of Hot Air they possess. As for application of trading emissions they will negotiate the shortage amount of Hot Air to a opponent who has the most amount of it in case that 
the amount is less than -10t. As for acceptance of trading emissions they will trade in case that the Hot Air amount is positive after acceptance of the deal.

\section{- Economy Type player}

Economy Type players make decisions on trading emissions based on the amount of money they possess. As for application of trading emissions they will negotiate the surplus amount of Hot Air to an opponent who has the short amount of it in case that the Hot Air amount is positive. Also they will do the difference amount from the minimum shortage amount, -20t. As for acceptance of trading emissions they will trade in case that it is profitable about the money at the end of the game after acceptance of the deal.

\subsubsection{Decision-Making on Trading Land}

Decision-making algorithms for trading land were developed after analyzing players' behaviors as was done for purchasing land. Application of trading land is judged by the possibility of monopoly of a color group of land and the surplus of Hot Air amount. The possibil- ity of monopoly means that a player can monopolize them if they possess the rest one land of the color group and an opponent has the land. Figure 5 shows the flow chart with the developed decision-making algorithms for acceptance of trading land. Acceptance of trading land is judged by Hot Air amount, comparison of land value, added money after acceptance of the deal. Land value based on ecological aspect (1-14.5) and land value based on economical aspect (1-9.3) are calculated by land price, charge and $\mathrm{CO}_{2}$ emission quota in the basic table as shown Table 1. Also based on the basic table the trade agreement possibility table is made for comparison of 2 lands of values including the added money by a player who applies and for judge of acceptance based on the possibility. follows.

The opponents make decisions on trading land as

\section{- Ecology Type player}

Ecology Type players make decisions on trading land based on the change amount of Hot Air they possess. As for application of trading land they will negoti-

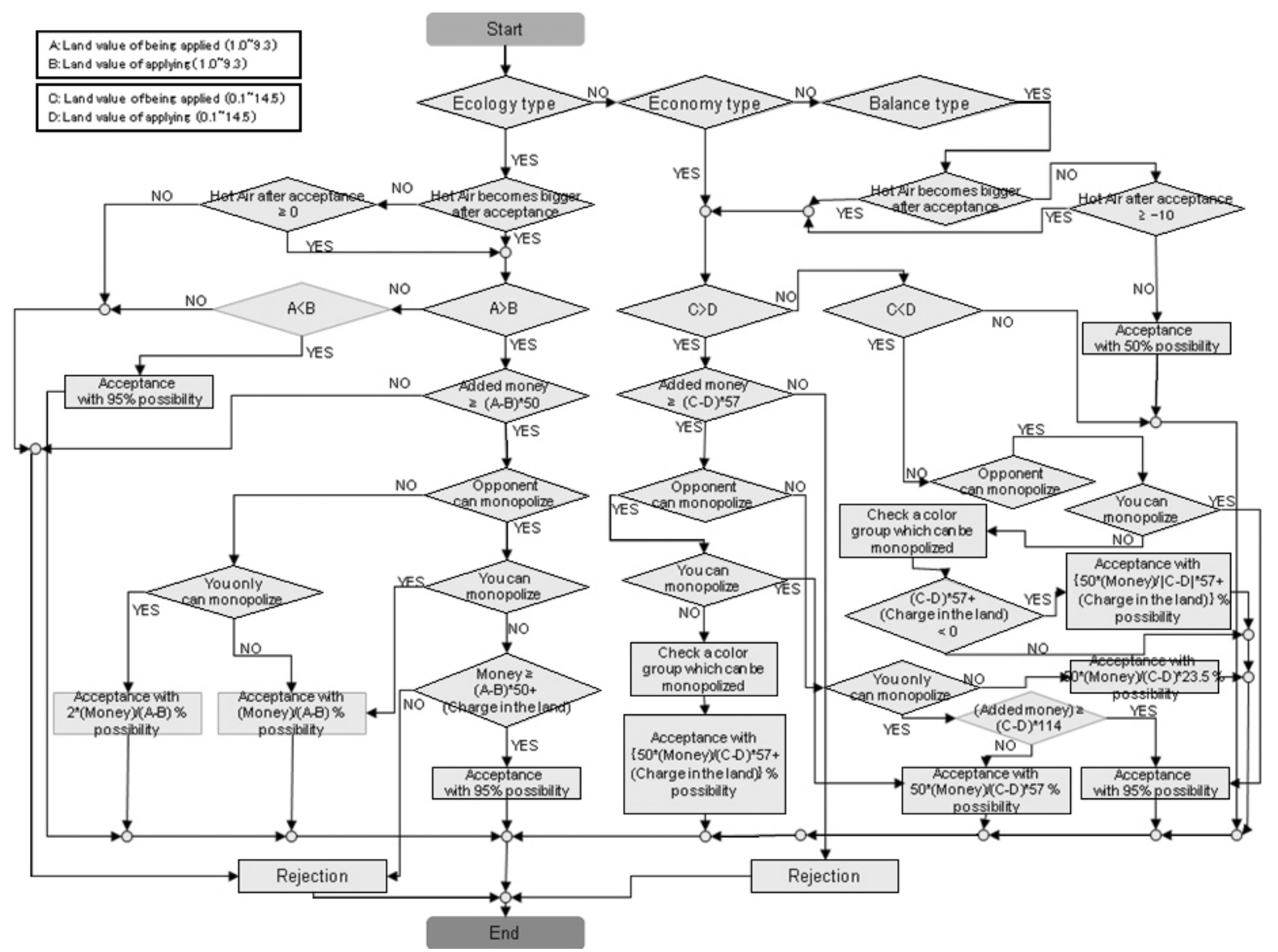

Figure 5. Flow Chart with the Developed Decision-Making Algorithms for Acceptance of Trading Land. 
ate in case that the Hot Air amount is positive after trading of the deal. As for acceptance of trading land they will trade in case that the Hot Air amount is positive after acceptance of the deal based on the trade agreement possibility table.

Table 1. Basic table of Land Value.

\begin{tabular}{|c|c|c|c|c|c|}
\hline Land Item & $\begin{array}{c}\text { Price of land } \\
(\mathrm{eco})\end{array}$ & $\begin{array}{c}\text { Charge } \\
(\mathrm{eco})\end{array}$ & $\begin{array}{c}\text { CO2 quota } \\
(\mathrm{t})\end{array}$ & $\begin{array}{c}\text { Land value of } \\
\text { Ecology type }\end{array}$ & $\begin{array}{c}\text { Land value of } \\
\text { Economy type }\end{array}$ \\
\hline \hline Portugal & 50 & 7 & 27 & 14.5 & 1.0 \\
\hline Greece & 50 & 8 & 25 & 13.9 & 1.0 \\
\hline Solar power plant & 80 & 20 & 10 & 9.3 & 1.8 \\
\hline Spain & 100 & 15 & 15 & 10.9 & 2.0 \\
\hline Ireland & 120 & 18 & 13 & 10.3 & 2.4 \\
\hline Iceland & 140 & 21 & 10 & 9.4 & 2.8 \\
\hline Sweden & 150 & 22 & 4 & 7.6 & 3.0 \\
\hline Norway & 180 & 28 & 1 & 6.7 & 3.6 \\
\hline New Zealand & 200 & 30 & 0 & 6.4 & 4.0 \\
\hline Wind power plant & 120 & 30 & 5 & 7.9 & 2.6 \\
\hline Vietnam & 210 & 42 & 0 & 6.4 & 4.4 \\
\hline India & 210 & 42 & 0 & 6.4 & 4.4 \\
\hline China & 230 & 46 & 0 & 6.4 & 4.8 \\
\hline Indonesia & 270 & 52 & 0 & 6.4 & 5.6 \\
\hline Brazil & 270 & 52 & 0 & 6.4 & 5.6 \\
\hline Thailand & 290 & 58 & 0 & 6.4 & 6.1 \\
\hline Nuclear power plant & 160 & 40 & -5 & 4.9 & 3.5 \\
\hline Japan & 350 & 54 & -6 & 4.6 & 7.1 \\
\hline Netherlands & 350 & 54 & -6 & 4.6 & 7.1 \\
\hline Canada & 350 & 54 & -6 & 4.6 & 7.1 \\
\hline Italy & 370 & 56 & -7 & 4.3 & 7.5 \\
\hline Czech Republic & 380 & 58 & -8 & 4.0 & 7.7 \\
\hline The United Kingdom & 410 & 62 & -13 & 2.5 & 8.3 \\
\hline Thermal power plant & 200 & 50 & -10 & 3.4 & 4.4 \\
\hline Denmark & 450 & 70 & -21 & 0.1 & 9.1 \\
\hline Germany & 460 & 72 & -21 & 0.1 & 9.3 \\
\hline
\end{tabular}

- Economy Type player

Economy Type players make decisions on trading land based on the change amount of money they possess. As for application of trading land they will negotiate with added money which amount is the difference of the two land values. As for acceptance of trading land they will trade in case that the difference of the two land values with added money is positive after acceptance of the deal based on the trade agreement possibility table.

\section{- Balance Type player}

Balance Type players make decisions on trading land based on the change amount of Hot Air and money they possess. As for application of trading land they will negotiate with added money which amount is the difference of the two land values in case that the Hot Air amount is positive after trading of the deal. As for acceptance of trading land they will trade in case that the Hot Air amount and the difference of the two land values with added money are positive after acceptance of the deal based on the trade agreement possibility table.

\subsubsection{Bankruptcy}

As the game proceeds, players may go bankrupt due to lack of money. In such cases, players must sell off some properties they possess. During the games conducted for analyses of decision-making processes, there was no case of bankruptcy observed. It was still possible to identify rough characteristics of each player type upon decision-makings. Since each player type has different priorities, lists of items to sell with different priorities and orders were designed for each player type, and relevant algorithms were developed.

\section{RESULT OF DEVELOPMENT AND EVALUATION OF ECOPOLY V}

\subsection{Development of Ecopoly $\mathrm{V}$}

The algorithms developed for the 6 decision-making matters according to each character type were built into the computer game version of Ecopoly. New screen pages were added to show the contents of automated computer opponents' decisions, and the self-learning computer version of the game on the environment, "Ecopoly V" was developed. As for the development environment, Microsoft Visual Basic 6.0 was used.

Figure 6 shows the chart of the overall structure of Ecopoly V, and its screen pages. At the beginning of the game, players should select if human players play the game and make decisions or let automated computer opponents play the game and make decisions automatically for each computer opponent from Ecology Type, Economy Type, and Balance Type. Also players can select language in Japanese, Korean and English.

When a turn completes, the player presses "Next Player" button to proceed the game. If the next player is an automated computer opponent, dice are thrown, the opponent makes decisions on the space the player landed, and the content of the decision is shown on the decision-making screen page shown in Figure 6, such as purchasing land and so on.

If an automated computer opponent monopolizes more than 1 color-group, decisions on forestation or factory construction are made automatically as well. Likewise, the choice of land and the number of implementations will be decided automatically. Also an automated computer opponent will negotiate for trading emissions or trading land to the others automatically.

\subsection{Evaluation of Developed Ecopoly $\mathrm{V}$}

Experimental testing of the developed program, Ecopoly V, was conducted in class, and 12 college students participated in the experiment as subjects. The subjects were given the game instruction booklets before the experiment, and were asked to read them before participating in the experiment. In class, the subjects were first asked to answer a quiz which contains questions on environmental problems and the extent of their knowledge was checked ( $5 \mathrm{~min}$.). After the quiz, the subjects took a lecture on various environmental problems caused on the earth and on the outline of the Kyoto Protocol, and finally on the outline and rules of Ecopoly V (25 min.). After this explanatory session, the subjects participated in the game (40 min.). After the game, the subjects joined a lecture on the relationship between the environment and the economy, which is the primary concept of the game designing ( $15 \mathrm{~min}$.), and answered the same quiz the subjects took before the game, filled in questionnaires about the game $(5 \mathrm{~min}$.).

The quiz consists of 10 multiple choice questions, 


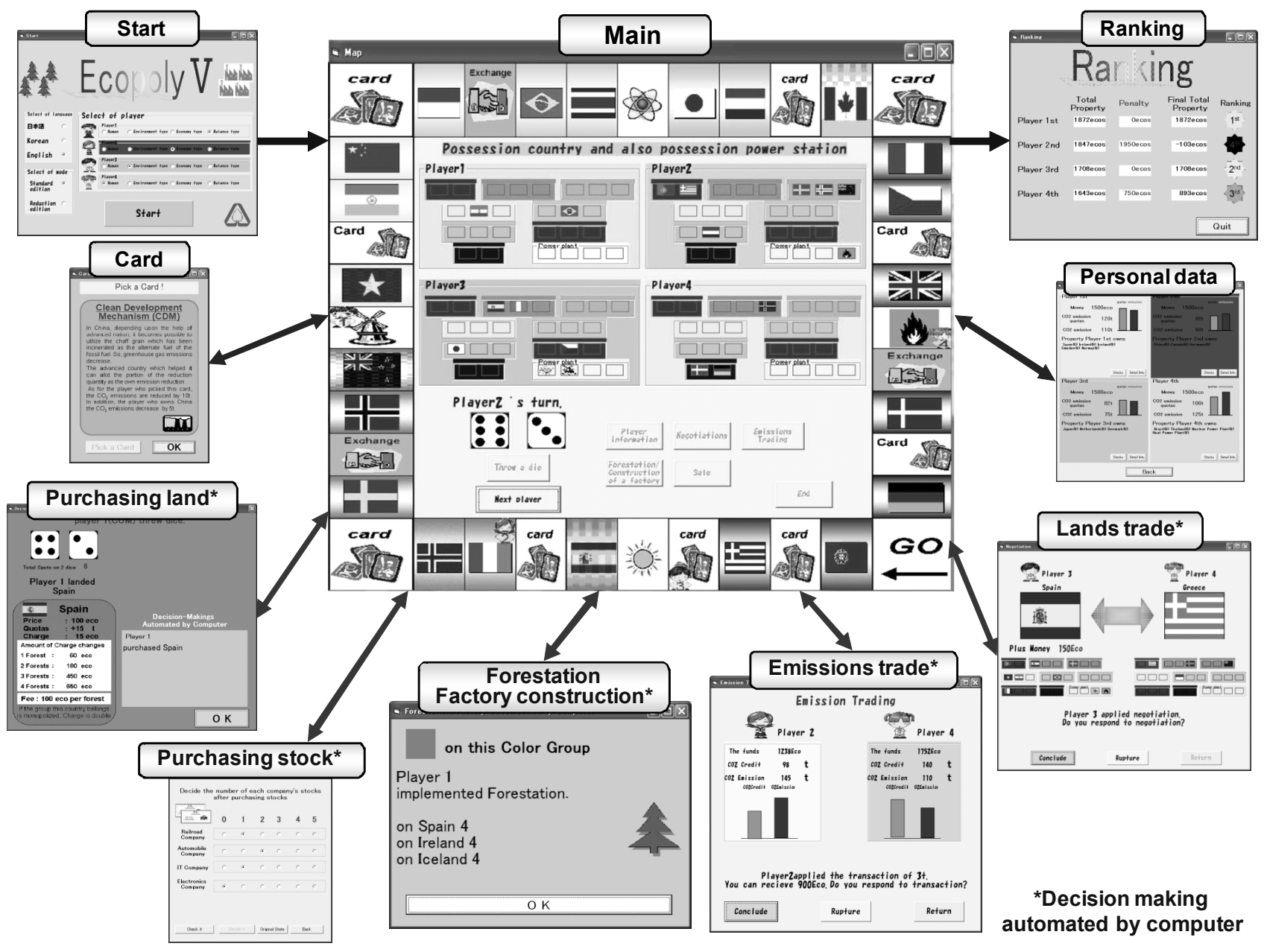

Figure 6. Overall Structure of Ecopoly V.

and the subjects were asked to work on the quiz before and after the experimental session, to verify the educational effects of Ecopoly V. During the game, the subjects have opportunities to draw cards, and the content of these cards are related to the content of the quiz. If the subjects read the cards carefully and understand the content, they can select the correct answers for the quiz. The result of the experiment shows that the average percentage of those questioned answered correctly among the 12 subjects rose from 5.9 questions before the experiment to 6.4 questions after the experiment. Also, the result of the t-test stands at a significant level of 5\%, and shows a significantly higher level $\left(\mathrm{t}(11)=1.9^{*}\right)$. It is thus possible to conclude that validity of the developed game in terms of environmental education was verified.

The subjects filled in the questionnaires after the experiment. According to the result, all the subjects answered they recognized the importance of balancing the environment and the economy, and $92 \%$ of the subjects answered the game Ecopoly $\mathrm{V}$ was fun to play. The result shows that the subjects enjoyed the game without focusing too much on studying through it, and that the game enabled the subjects to recognize the importance of the balance between the environment and the economy at the same time.

From above, it is possible to conclude that an educational tool which enables students to have fun playing games and to learn about the environment effectively has been successfully developed without affecting the educational quality and effectiveness that Ecopoly provided.

\section{CONCLUSIONS}

In this study, the authors have developed a computer game Ecopoly $\mathrm{V}$ with automated decision-making based on Ecopoly. In the computer game, players can learn about the environment by themselves through playing the game against computer opponents whose decision-making processes are automated. Upon development, firstly, the experimental game sessions using the board game were held 5 times, totally played in 750 minutes by 10 college students as subjects. Based on the 
observations and decision-making notes filled out by the subjects, 6 decision-making matters: purchasing land, forestation and factory construction, purchasing stock, trading emissions, trading land and bankruptcy were analyzed. As for purchasing land, forestation and factory construction, purchasing stock, trading emissions and trading land, the authors could specify the characteristics of decision-making processes, and the features and respective player types were categorized into 3 player types "Ecology Type," "Economy Type," and "Balance Type." Decision-making algorithms were then developed for each player type based on the characteristics identified through analyses. As for bankruptcy, algorithms were developed based on the presumed decisionmaking processes. The developed algorithms and decision-making processes were built into the computer version of Ecopoly, with the new screen pages added for showing the contents of decisions made by automated computer opponents. The developed game was used in an experiment session, joined by 12 college students as subjects, and the educational effects of the game was verified. Therefore, the authors have succeeded in realizing the development of self-learning computer game Ecopoly V.

As future issues, the authors would like to make sure the parameters of decision-making by simulations and also develop other education materials which treat ecological behaviors or the real world scenario on environmental issues.

\section{ACKNOWLEDGEMEZNT}

This study is funded by Grant-in-Aid for Scientific Researches (numbered 20500785). The authors would like to express their gratitude to the organization.

\section{REFERENCES}

Axelrod, A. (Author), Daichi S. (Translator) (2004), Everything I Know About Business I Learned From Monopoly (in Japanese), DIAMOND-SHA, ISBN 0-7624-1694-7.

Kaneko, K., Fujita, K., and Baba, M. (2004), Recommendation of New Environmental Education (in
Japanese), Nikkei Ecology, 10, 24-37.

Kawato, M. and Chikamori, K. (2005), A Study of Environmental Education for Energy, Journal of Conference on Energy, Economy, and Environment, 21, 239-242.

Komuro, T. and Matsumoto, T. (2009), Development of a Board Game 'Ecopoly' for Education on Relationship between Environment and Economy (in Japanese), Transactions of Japanese Society for International and Systems in Education, 26(4), 339348.

Komuro, T. and Matsumoto, T. (2011), Development of a Computer Game 'Ecopoly' for Education on Relationship between Environment and Economy, The Journal of Industrial Engineering and Management Systems, 10(4), 264-271.

My Earth Projects LLC, My Earth, http://myearth.ne.jp.

Saito, S. and Yamane, K. (2007), Evolving Environmental Education (in Japanese), Nikkei Ecology, 6, 24-37.

Salisbury, L., Zucker, P., Tazaki, H., and Yamazoe, M. (2005), Delicate Relationship between $\mathrm{CO}_{2}$ Emissions Quota and Post Kyoto (in Japanese), Nikkei Ecology, 7, 128-129.

Sugimoto, M., Kusunoki, F., Inagaki, S., Takatoki, K., and Yoshikawa, A. (2002), A System for Supporting Collaborative Learning with Networked Sensing Boards (in Japanese), Journal of the Institute of Electronics, Information and Communication Engineers, J85-D1(12), 1152-1163.

Suguru, K. (1999), MONOPOLY Club (in Japanese), TBS-BRITANNICA, ISBN 4-484-99216-7.

Tenmei, S., Hayasaka, K., and Matsumoto, T. (2010), Improvement of the Game to Educate Balance between Ecology and Economic (in Japanese), Proceedings of the 22th Fall Conference on Japan Industrial Management Association, 30-31.

The Ministry of Foreign Affairs of Japan: Global Warming Issue, http://www.mofa.go.jp/mofaj/gaiko/kan kyo.

The Ministry of Environment of Japan: United Nations Framework Convention on Climate Change/Chart of Ratifies in the Kyoto Protocol, http://www.env. go.jp/earth/ondanka/mechanism/. 